\title{
QUANDO O COTIDIANO INTERROGA O CURRÍCULO: OUTROS MODOS DE PENSAR A DOCÊNCIA NA EDUCAÇÃO INFANTIL
}

\author{
WHEN DAILY QUESTION CURRICULUM: other ways to think of education in childhood education
}

CUANDO EL CURRÍCULO DE PREGUNTAS DIARIAS: otras maneras de pensar en la educación en la educación infantil

\author{
RORATO, Adriana 1 \\ MELLO, Elena Maria Billig 2
}

\section{RESUMO}

Esse estudo é parte de uma pesquisa-ação desenvolvida a nível de mestrado acadêmico cujo objetivo principal foi investigar desafios e possibilidades que atravessam os movimentos de (re)invenção curricular em uma escola de Educação Infantil. Após a organização dos dados com o software Atlas.ti, na análise textual discursiva emergiram discussões com enfoque crítico, levantando questões como a desnaturalização de concepções de criança, infâncias, além dos enfoques atribuídos a espaçostempos e materialidades em creches e pré-escolas. Foram articuladas ainda questões relacionadas à autonomia pedagógica e aos processos de autoria crítica enquanto possibilidades para o reposicionamento docente.

Palavras-chave: Educação Infantil. Currículo. Cotidiano.

\section{ABSTRACT}

This study is part of an action research developed at the academic masters level whose main objective was to investigate challenges and possibilities that cross the movements of (re)invention of the curriculum in a preschool. After data organization with Atlas.ti software, in the discursive textual analysis critically focused discussions emerged, raising issues such as the denaturalization of child conceptions, childhoods, as well as the approaches attributed to space-time and materialities in daycare centers and preschools. Questions related to pedagogical autonomy and critical authorship processes were also articulated as possibilities for teacher repositioning.

Keywords: Early Childhood Education. Curriculum. Daily.

\section{RESUMEN}

Este estudio es parte de una investigación de acción desarrollada a nivel de maestría académica cuyo objetivo principal era investigar los desafíos y las posibilidades que atraviesan los movimientos curriculares de (re) invención en una escuela de la primera infancia. Después de organizar los datos con el software Atlas.ti, en el análisis textual discursivo, surgieron discusiones con un enfoque crítico, planteando cuestiones como la desnaturalización de las concepciones de los niños, la infancia, además de los enfoques atribuidos al espacio-tiempo y las materialidades en guarderías y centros preescolares. Las cuestiones relacionadas con la autonomía pedagógica y los procesos de autoría crítica también se articularon como posibilidades para el reposicionamiento del maestro.

Palabras clave: Educación de la primera infancia. Plan de estúdios. La vida cotidiana.

\footnotetext{
${ }^{1}$ Universidade Federal do Pampa - UNIPAMPA - Bagé - Rio Grande do Sul - Brasil.

${ }^{2}$ Universidade Federal do Pampa - UNIPAMPA - Uruguaiana - Rio Grande do Sul - Brasil.
} 


\section{INTRODUÇÃO}

A Educação Infantil vem forjando a si mesma ao longo dos tempos, entre lutas e conquistas, modelos, imitações, construções, avanços e retrocessos. Nesse cenário, é oportuno pensarmos nas transformações-desafios que incidem na construção cultural da professoralidade ${ }^{3}$, interrogarmos a docência na Educação Infantil em suas tensões e contradições, desnaturalizarmos concepções, ações, tradições, ainda tão formatadas a partir dos modelos do Ensino Fundamental.

Ao dialogar sobre a invenção da docência com crianças de 0 a 5 anos e 11 meses, a busca por respostas a diversos questionamentos aponta para uma necessária revisão nos sentidos que a flexibilidade dos processos assume na Educação Infantil, diálogo que precisa abarcar o currículo vivo nas instituições, considerando a potência de crianças e bebês.

Assim, entendendo as múltiplas dimensionalidades do currículo em seus (entre)laçamentos, o objetivo geral desta pesquisa foi investigar desafios e possibilidades que atravessam os movimentos de (re)invenção curricular em uma escola de Educação Infantil. As leituras de Moreira e Silva (1995) e Lopes e Macedo $(2010 ; 2011)$ foram fundamentais para ancorarmos as questões e os olhares que encaminharam os rumos das investigações levantadas neste estudo.

A aproximação entre universidade e educação básica deu-se a partir da abordagem metodológica da pesquisa-ação, enquanto tentativa de superar o distanciamento entre as produções acadêmicas e o cotidiano das escolas. Especialmente escolhida para esta pesquisa por seu caráter participativo e democrático, a pesquisa-ação potencializou o alcance de respostas numa perspectiva relacional, repleta de tramas, saberes, sentimentos e significados.

Englobando duas tarefas simultâneas, pesquisa e ação, esta metodologia proporcionou alcance transversal e horizontalizado, permitiu dar voz aos sujeitos de pesquisa, compreendendo e qualificando debates e ações sob forma de diretrizes emancipatórias, não se limitando apenas à descrição ou avaliação de contextos (THIOLLENT, 1986; TRIPP, 2005; FRANCO, 2005).

O processo de construção de dados ganhou enfoque a partir dos diálogos e produções de 10 (dez) sujeitos ${ }^{4}$ da Escola Municipal de Educação Infantil Zezé Tavares - Bagé/RS 5 , território privilegiado para viver-pesquisar por dentro o cotidiano institucional, no que se refere aos espaçostempos de encontros e reflexões, devido à vinculação das autoras deste artigo com o lócus da pesquisa.

\footnotetext{
${ }^{3}$ A ideia de professoralidade tem ancoragem em Oliveira (2003), que concebe a (re)construção do sujeito docente em espaços-tempos ao longo de toda a sua trajetória pessoal e profissional.

${ }^{4}$ A escolha dos 10 (dez) sujeitos de pesquisa levou em consideração tanto a representação das etapas da Educação Infantil atendidas pela escola (berçário, maternais 1 e 2, e pré-escola) quanto dos segmentos da comunidade escolar (professoras, funcionárias e equipe diretiva), tendo em vista a representatividade sociopolítica desta amostra intencional enquanto membros ativos nos espaços-tempos que compõem a escola pesquisada.

${ }^{5}$ Tendo em vista a base epistemológica desta pesquisa já sustentada, em que os processos de (re)invenção curricular se dão a partir dos contextos e dos sujeitos neles envolvidos, solicitamos autorização para utilizar os nomes reais das dez profissionais que foram sujeitos desta pesquisa. Esta decisão coaduna com as premissas da pesquisa-ação, que valoriza a trajetória dos sujeitos e processos vividos, dá voz a suas concepções e práticas que não são fictícias, mas social e culturalmente ancoradas.
} 
Assim, nesta investigação propomos pensar Educação Infantil e sociedade em relação dialógica, com múltiplas determinações da (re)produção da vida social, relativizando categorizações e polarizações frequentes entre instituições educativas ou assistenciais, articulando intenções, compreendendo-as enquanto construções sociais, territórios políticos, nos quais saber e poder estão intimamente conectados.

O currículo associado ao cotidiano, como um balizador de ações ancorado nos sujeitos e nos espaços-tempos da Educação Infantil, relacionado com diversos elementos presentes na cultura escolar, é, assim, concebido como fundamento base para o repensar de ações/intenções que considerem as infâncias em suas multiplicidades, gestado a partir do exercício da participação, da coletividade, do compartilhamento do poder, da tomada de decisões, intenções e rumos.

Ao trazer para a discussão os elementos da pesquisa, mais do que apresentar resultados, desafiamo-nos a narrar os processos de interpretar e compreender o currículo em seu caráter multidimensional, num esforço para desfazer as amarras reducionistas do cotidiano vivido e investigado, aspectos que passamos a sublinhar na próxima seção.

\section{CAMINHOS INVESTIGATIVOS}

Pensar sobre currículo numa perspectiva crítica tem sido tarefa das mais instigantes em meio às tensões vividas num período marcado por retrocessos no que se refere às políticas educacionais brasileiras, com a emergência de postulados tecnicistas, controladores e gerenciais de currículo. Mergulhar em leituras e reflexões críticas, densas, ou "envenenadas", como diria Carbonell (2016), permitiu que muitas questões fossem ficando mais nítidas, nuances e enfoques percebidos com maior profundidade em suas relações, seus interesses e influências.

Nesses caminhos, preocupamo-nos, principalmente, em assumir a rigorosidade e a complexidade que a perspectiva crítica exige, tomando a decisão de privilegiar nesta investigação uma postura ética na participação e emancipação dos indivíduos, os quais assumiram a condição de sujeitos e não de objetos da pesquisa.

Se "[...] a questão do currículo é a questão central que diz respeito àquilo que a escola faz e para quem faz ou deixa de fazer." (BERTICELLI, 1998, p. 159), compreendermos a complexidade deste campo, especialmente no que se refere aos seus rastros híbridos ${ }^{6}$, é central para aprofundarmos elaborações e estabelecermos outros nexos possíveis entre sujeitos, cenários e movimentos em forma de macro/micro políticas curriculares.

Nessa perspectiva, passagens e descaminhos que emergem do cotidiano permitem que o estabelecimento de relações considere questões até então marginalizadas no que se refere à produção curricular, num fluxo de sentidos movediço e indeterminado. Em diálogo com Oliveira (2016, p. 73-74), pensar currículo desta maneira,

6 Lopes e Macedo (2010) abordam o hibridismo como uma marca do campo do currículo, o qual exige uma rede múltipla de referências para sua interpretação. A este fator atribuem tanto os processos de potencialização do campo quanto a dificuldade em definir o que vem a ser currículo. 
[...] entendido como entre-lugar é falar de uma produção que se dá nos excedentes das somas das partes [...] Uma soma equivalente que não apaga as diferenças, mas as coloca em diálogo [...] as suas relações, articulações e negociações se dão através de fluxos de discursos (globais e locais), de perspectivas, de posições, de poderes, de identidades, de diferenças, de políticas, de conhecimentos, cotidianos e traduções.

Nessa direção, compreender currículo numa perspectiva holística e processual, a partir do entendimento de criança enquanto sujeito histórico, pressupõe vislumbrarmos a Educação Infantil numa visão política, comprometida com a multiplicidade/singularidade de crianças/infâncias que dela fazem parte. Assim, ao experienciar uma pesquisa profundamente viva, permitimo-nos prestar especial atenção ao trivial, vislumbrar o comum com atenção incomum para, a partir deste cotidiano em linguagem da vida, elaborarmos respostas provisórias aos questionamentos que impulsionaram esta investigação.

Nessa perspectiva, ao acompanharmos o fluxo dos movimentos vividos pelas profissionais de uma escola de Educação Infantil, experimentamos viver a metodologia no processo de investigação e nos aproximamos da potência que move tais sujeitos a criar, inovar e refletir em/sobre seu campo de atuação. Nessa tarefa, o próprio contexto do cotidiano apontou instrumentos para tecermos um conjunto de dados rico em indicativos, concepções e enfoques curriculares.

A gravação de áudio durante seminário de partilha docente, ocorrido internamente na escola com toda a equipe de profissionais tornou-se o primeiro instrumento de pesquisa. Nesta etapa, atividade prevista no calendário da Instituição, as docentes elaboraram material em formato de síntese para apresentação multimídia, abarcando aspectos que destacaram como centrais em sua prática pedagógica, utilizando para isso fotos e outros registros ilustrativos.

Tal síntese originou-se de outro recurso, que também fora instrumento de pesquisa: resumos expandidos, com introdução, procedimentos metodológicos, resultados e reflexões e referências, registrados por cada docente da escola. Mais amplo e profundo, este instrumento culminou na organização de um e-book $k^{7} \mathrm{com}$ as produções e ressignificações do grupo de professoras da Instituição.

A imprevisibilidade também teve espaço na construção de dados: o terceiro instrumento, com recursos imagéticos, surgiu a partir de uma reunião em que a equipe criou uma dinâmica interna denominada "essência Zezé". Na oportunidade, toda a equipe de profissionais da instituição foi desafiada a escolher criativamente uma representação visual para simbolizar o modo como vislumbram as propostas e ideais da escola, apresentando ao grupo.

O último instrumento, em processo recursivo, recuperou questões implícita ou explicitamente levantadas pelos sujeitos da pesquisa sobre currículo e inovação pedagógica nos três momentos anteriores. Quatro questões provocadoras foram elencadas para fomentar o diálogo junto ao grupo focal ${ }^{8}$, gravadas em áudio e, posteriormente, transcritas, a saber: 1) O que te levou a escolher esta representação visual para a "essência Zezé"?; 2) Acreditas que há inovação pedagógica no currículo

\footnotetext{
${ }^{7}$ Disponível em: http://dspace.unipampa.edu.br/jspui/handle/riu/4639.

${ }^{8}$ A ideia de grupo focal encontra respaldo em Gatti (2005) enquanto técnica dialética que permite a compreensão de perspectivas nos discursos dos sujeitos, sendo suas experiências consideradas não somente em seu conteúdo, mas nas divergências e contraposições possíveis de serem interpretadas.
} 
da escola? Por quê?; 3) Que desafios você ainda vê como importantes para a (re)construção contínua do currículo da escola? e 4) Que aspectos você considera como facilitadores/dificultadores para a inovação pedagógica no currículo da escola?.

$\mathrm{Na}$ intenção de compreendermos esta dinâmica enquanto dialética em seus movimentos contínuos de (des)construção e de emergência de significados relacionados aos fenômenos investigados, optamos por nos aproximar da Análise Textual Discursiva - ATD (MORAES; GALIAZZI, 2007) como possibilidade de atingir uma qualidade formal e política com os resultados da pesquisa, impulsionada pelo uso do software Atlas.ti9 (FRIESE, 2019), ferramenta que suscita a criação de redes de conexões autorais desde o início do processo analítico.

Embasadas nos pressupostos das leituras de Moraes e Galiazzi (2007), nos estudos de Ariza et al. (2015) e de Salomão de Freitas (2015) sobre as articulações metodológicas entre ATD e ATLAS.ti, elaboramos uma tabela comparativa em que sintetizamos as aproximações identificadas entre os elementos de ambos, a qual apresentamos a seguir:

Tabela 1: Comparação entre os elementos do ciclo da ATD e os recursos do software ATLAS.ti

\begin{tabular}{|l|l|}
\hline \multicolumn{1}{|c|}{ Ciclo da ATD } & \multicolumn{1}{|c|}{ Recursos do ATLAS.ti 8.0 } \\
\hline Parte do corpus investigativo & Documentos primários \\
\hline Desmontagem dos textos em Unidades de Significado & Citações livres \\
\hline Estabelecimento de relações, com a categorização & Códigos \\
\hline $\begin{array}{l}\text { Envolvimento e impregnação com o corpus, expressando } \\
\text { em forma de argumentos os principais insights }\end{array}$ & Memos \\
\hline $\begin{array}{l}\text { Emergência de uma compreensão renovada do todo, com } \\
\text { uma nova combinação dos elementos em forma de } \\
\text { metatexto }\end{array}$ & Redes estruturais \\
\hline
\end{tabular}

Fonte: Autoras (2019)

As possibilidades crítico-analíticas da ATD enquanto abordagem indutiva de dados impulsionaram a produção de significados singulares ${ }^{10}$, processo em que a compreensão dos fenômenos configurou-se em movimentos interpretativo-argumentativos repletos de subjetividade, os quais passamos a abordar nas próximas seções.

\footnotetext{
${ }^{9} \mathrm{O}$ ATLAS.ti é um programa de computador desenvolvido para análises qualitativas, uma bancada de trabalho que fornece ao pesquisador múltiplos instrumentos para o gerenciamento e a sistematização de uma análise interativa, complexa e autoral.

${ }^{10}$ RORATO, Adriana. A inovação pedagógica nos (entre)laçamentos curriculares da Escola Municipal de Educação Infantil Zezé Tavares. 167p. 2019. Dissertação (Mestrado em Ensino) - Universidade Federal do Pampa UNIPAMPA, Programa de Pós-Graduação em Ensino, Bagé/RS, 2019. Disponível em: http://dspace.unipampa.edu.br/handle/riu/4758. Acesso em 06 maio 2020.
} 


\section{ENTRE AS POLÍTICAS-PRÁTICAS CURRICULARES DA EDUCAÇÃO INFANTIL}

Com cerca de um século de existência, a Educação Infantil brasileira vive ainda hoje uma busca por legitimar sua identidade, pelo reconhecimento de suas especificidades tanto conceituais quanto metodológicas. Nesse processo, marcado por diversas transformações paradigmáticas, à medida que as concepções de criança e de infância foram sendo alteradas de acordo com os contextos sociais de cada época, também as instituições que abrigavam crianças dos 0 aos 6 anos de idade foram adequando-se às transformações e sofrendo os reflexos de cada período.

Assim, refletir sobre as concepções curriculares no campo da Educação Infantil brasileira pressupõe, inicialmente, dialogar acerca da complexidade conceitual destes tópicos, envoltos em meio a disputas teóricas e políticas, refletidas nos modelos adotados, nas intenções e ações docentes, nas concepções de conhecimento, aprendizagem, ensino. Esse diálogo perpassa necessariamente os desafios que se apresentam aos profissionais da Educação Infantil ao enfrentar um grande descompasso entre o normatizado e as condições sociais, políticas, econômicas e culturais da prática cotidiana. (ROSEMBERG, 2014).

Criar, recriar, formular pedagogias num contexto de ausência de identidade própria dos profissionais da Educação Infantil representa uma pressão que é latente aos dissensos do próprio campo (HADDAD et al., 2012): a forte controvérsia das políticas e práticas de creches e pré-escolas, desde sua origem é marcada por uma dicotomia entre cuidado e educação, pólos que tem reiterado enfoques, debates e regulações nos rastros dessa história.

Por muito tempo, a oferta de atendimento às crianças em creches e pré-escolas esteve vinculada aos órgãos governamentais de serviço social, cenário que se configurou durante o processo de redemocratização brasileira, com a realização de amplos debates e reivindicações por parte de movimentos sociais e operários. Estas instituições destinavam-se à guarda e à assistência das crianças carentes, oferecendo cuidados de higiene e alimentação como um favor, ligado estreitamente à prevenção da criminalidade, à promoção da segurança e da saúde, demarcando a natureza de direito social da Educação Infantil.

Kuhlmann Júnior (2015) atenta para o desenvolvimento de uma pedagogia da submissão como concepção político-pedagógica que marcava o currículo das instituições direcionadas para as camadas populares:

As concepções educacionais vigentes nestas instituições se mostravam explicitamente preconceituosas, o que acabou por cristalizar a ideia de que, em sua origem, no passado, aquelas instituições teriam sido pensadas como lugar de guarda, de assistência, e não de educação. (KUHLMANN JÚNIOR 2015, p. 166).

Os movimentos dialéticos de busca por uma identidade das/para as instituições de Educação Infantil tornam claro que, em contraposição à assistência, a adoção/reprodução do modelo escolarizante na Educação Infantil se deu pela intenção de legitimar sua função educativa, na tentativa de reiterar seu cunho de ensino, assumindo uma lógica de preparo para a escolarização futura, de 
favorecer uma prontidão para a alfabetização e evitar o fracasso escolar.

A ausência de uma política que garantisse os direitos das crianças ao acesso e à qualidade de atendimento em instituições de Educação Infantil evidenciou a urgente necessidade de ações legislativas, de forma a definir objetivos e diretrizes que reorientassem as ações pedagógicas destinadas às crianças de 0 a 6 anos.

De fato, a subordinação do atendimento de creches e pré-escolas ao sistema educacional pela Constituição Federal de 1988 representou um grande passo nessa direção, legitimado posteriormente pela Lei de Diretrizes e Bases n 9.394/96, que ratificou a Educação Infantil como direito social, dever do Estado e como primeira etapa da Educação Básica.

Ao reconhecer as crianças como cidadãs e sujeitos de direitos, esses dispositivos legais inauguraram um novo cenário na história da Educação Infantil, consolidando seu reconhecimento como primeira etapa da Educação Básica e passando a exigir a formação dos profissionais que nela atuam, mobilizando a ampliação e qualificação de sua oferta.

Cabe aqui ponderarmos acerca dos distanciamentos entre o estabelecido em âmbito legal e sua efetivação, problematizarmos ações e a qualificação do campo da Educação Infantil, tendo em vista importantes avanços alcançados, mas também demandas desconsideradas e desafios latentes.

Do ponto de vista legal, a passagem da criança de sujeito de tutela a sujeito de direitos pressupõe uma perspectiva que percebe seu potencial humano em suas múltiplas formas de expressão, enquanto protagonista e co-construtora de cultura. Em contrassenso, nossa sociedade ainda é marcada pelo desrespeito às potencialidades e perspectivas das crianças, com infâncias, muitas vezes, marcadas pela negligência, pelo trabalho infantil, pelo assédio, pela escolarização precoce.

Esses processos de disputas e reconfigurações, que atravessam o currículo da/para a Educação Infantil, ganham novos contornos e proporções, (des)encontros, confrontos, (contra)pontos à medida que reformas educacionais são gestadas e implementadas em nosso país.

$(\mathrm{Re})$ contextualizar as políticas curriculares nos espaços-tempos escolares, enquanto centros decisórios de (des/re)construção de sentidos (LOPES; MACEDO, 2011), implica enfrentar desafios e tensionamentos, sem que haja a proclamação de uma colonização dependente dos grupos hegemônicos econômica e culturalmente (MACEDO, 2006), assumindo múltiplas perspectivas na busca de alternativas curriculares condizentes com contextos e condições.

Nesse sentido, ao vislumbrarmos as instituições de Educação Infantil como lugares com função sociopolítica e pedagógica, apontamos para a urgência no rompimento com os modelos assistencialista e escolarizante, que, por tanto tempo marcaram - e ainda marcam - esta etapa educacional, com a necessidade de:

[...] analisar formas de olhar para o cotidiano das unidades e percebê-lo como fonte de pesquisa de ações que contribuam para qualificar as aprendizagens das crianças e pesquisar como mediar cada unidade a compreender seus problemas institucionais para poder optar, por meio de processos compartilhados, por intervenções apropriadas e coerentes com determinados princípios. (OLIVEIRA, 2014, p. 193). 
Nessa perspectiva, as análises desta pesquisa apontaram para a necessidade de pensarmos a docência na Educação Infantil de outros modos, alicerçada em movimentos complexos e intensos de retroalimentar a própria formação docente e construir sentidos para as experiências vividas pela constituição de espaços de formação e reflexão. Qualificar práticas docentes na Educação Infantil perpassa um grande esforço de criação em que precisamos tensionar perspectivas lineares, soluções simplificadoras ou adaptações a partir de propostas elaboradas para crianças maiores, questões que passamos a discutir na próxima seção.

\section{PLURALIZANDO SENTIDOS PARA UM CURRÍCULO-COTIDIANO}

Olhar por outros nexos a docência na creche e na pré-escola na contemporaneidade implica (re)começarmos as próprias trilhas enquanto profissionais, arriscarmos a renovar perspectivas, perseguirmos - ou nos colocarmos - interrogações e inquietudes, o que para Barbosa (2009, p. 37) significa que: "Numa nova perspectiva, compreende-se o papel do professor como o de um orientador da busca do conhecimento, principalmente quando ela surge como necessidade para desenvolver o projeto do grupo e as necessidades e desejos individuais das crianças.".

Pensar nestes processos em tessitura nas redes cotidianas, impregnados de interpretação e tomadas de decisão, leva-nos a assumir o cotidiano escolar como espaço-tempo de diálogo e reflexão intermináveis sobre outros fazeres e saberes, outros interesses e curiosidades, outras crenças e valores. Apostar na reinvenção, na negociação de sentidos pressupõe criar itinerários próprios, assumirmos a autoria tensionada e coletiva das várias dimensões de um currículo.

A construção de dados trouxe, nas vozes dos sujeitos da pesquisa, indicativos que remetem a estas questões: "porque a gente tá arraigado ainda a paradigmas que são impostos" (JOSI5GF) , "o quanto a gente tá envolvido aqui com educação, com educação infantil, a gente não se perder no caminho e achar que nós somos ensino [...] nós temos que ver que nós somos educação infantil e nós temos que abranger todos esses momentos que acontecem na vida da criança" (CÁT3GF).

Nesses processos subjetivos de construção profissional, as contradições podem fomentar atritos provisórios, a negação de perspectivas pode estimular debates, as dúvidas e incertezas podem impulsionar outras articulações e encaminhamentos. Nos afastarmos de posições unilaterais e de verdades absolutas representa uma abertura a outras formas de pensar a docência que não restrita a tradições, cronogramas e linearidades que, fundamentalmente, controlam o professor.

A passos lentos e ásperos, esses e outros ranços no campo da Educação Infantil vem sendo postos em evidência. Pensar a partir de quais lógicas estamos concebendo o currículo e a docência possibilita sua (re)significação e a tomada de decisões conscientes sobre posições, cenários e seleções ofertadas às crianças na Educação Infantil (RICHTER, 2016). A disseminação de estudos e pesquisas tendo como foco a primeira infância tem contribuído para uma compreensão cada vez maior acerca do desenvolvimento infantil, da articulação entre pressupostos de educação e cuidado de forma intencional nas instituições de Educação Infantil.

Corroborando com essa discussão, Bujes (2001) salienta que, num retrospecto histórico, um conjunto de ideias, assentado em condições particulares, normatizado de forma arbitrária, foi 
disseminado por muitas gerações, influenciando as instituições e formas de atuação dos profissionais na Educação Infantil. Essas são marcadas ainda hoje pelo disciplinamento, pela submissão e pela escolarização precoce, especialmente na pré-escola, desconhecendo "[...] um modo atual de ver as crianças: como sujeitos que vivem um momento em que predominam o sonho, a fantasia, a afetividade, a brincadeira, as manifestações de caráter subjetivo." (BUJES, 2001, p. 17).

Em diversos contextos durante a construção de dados, essas questões estiveram em pauta: "tu vai construindo, tu vai vendo, tu vai vivenciando, tu vai pensando: porque que eu tô fazendo isso?" (CÁT5S), "o que que a gente fazia [...] a gente fazia aquela papagaiada passinho pra cá, passinho pra lá, dança pra cá, dança pra lá" (MARI3GF), "observar, registrar, identificar e aprimorar a proposta pedagógica da professora em relação ao desenvolvimento da linguagem, do pensamento lógico, da imaginação, socialização, construção da identidade e autonomia, tendo como base os mais variados modos de brincar das crianças" (CLA3EB).

A docência na Educação Infantil exige, na atualidade, o confrontar de programações e/ou listas de atividades, de reproduções, homogeneizações, progressões sequenciais de aprendizagens. Exige a intensificação de debates sobre as apostas e os desafios específicos de cada conjuntura, entre condições e limitações no que se refere ao exercício e à formação-profissão docente, refletindo sobre demandas importantes como:

[...] a ausência de problematização diante da opção pelas áreas de conhecimentos, a falta de discussão sobre o tempo e o espaço dos bebês, a desconsideração pelo movimento lúdico do corpo, a separação entre conteúdo e metodologias, entre aprendizagem das crianças e ação pedagógica dos professores, entre conteúdo escolar e cultura [...]. (BARBOSA; RICHTER, 2015, p. 189-190).

Segundo Barbosa (2009, p. 12), a Educação Infantil assume na contemporaneidade a função de "[...] possibilitar a vivência em comunidade, aprendendo a respeitar, a acolher e a celebrar a diversidade dos demais, a sair da percepção exclusiva do seu universo pessoal, assim como a ver o mundo a partir do olhar do outro [...]". Dessa forma, a experiência curricular na Educação Infantil implica o desenvolvimento de ações que articulem os saberes das crianças com os conhecimentos do patrimônio cultural através de relações sociais, seguindo princípios éticos, políticos e estéticos (BRASIL, 2009).

Ao problematizarmos as especificidades da ação docente na Educação Infantil, questões intrínsecas ao currículo são tocadas, numa relação dialógica e interdependente. As tentativas de compreender com maior profundidade elementos constituintes do currículo, nessa perspectiva de contínua (re)invenção, perpassam a hibridez de relações, atuações, concepções, intrínsecas a estas interlocuções complexas e dinâmicas.

A escola como lugar de encontro requer a criação de experiências compartilhadas, demanda diálogo e a atribuição de outros sentidos para os espaços-tempos, outras valorizações para o cotidiano em sua simplicidade e extraordinariedade em que: "Torna-se necessário captar os elementos sensíveis da vida cotidiana e relacioná-los aos processos sociais, históricos e políticos para que os mesmos façam sentido para as crianças e ofereçam para elas outros olhares e modos de viver." (BARBOSA, 2013, p. 219). 
Esse caminho epistemológico, repleto de imprevisibilidade, parte das crianças para a organização de espaços-tempos, intenções, direções e sentidos para a ação pedagógica, numa criação de contextos e experiências lúdicas que provocam brincadeiras e interações. Essa referência às crianças como sujeitos protagonistas de suas atuações e aprendizagens foi sinalizada em excertos da construção de dados, tais como: "nos dão suporte para que continuemos sem rotina fixa ou preestabelecida, mas elaborada continuamente a partir dos indícios que as crianças nos dão" (CAM8EB); "desenvolvidos por prováveis etapas, sempre replanejadas a partir das devolutivas das crianças com a observação atenta a suas manifestações, abertura e flexibilidade para replanejar ações e intenções" (MARITEB).

Subjacentes a esses discursos estão contidas concepções de criança, infância e aprendizagem que perpassam potência e multiplicidade, indicadores que servem como eixos norteadores para planejamentos e interações. Nessa direção, perceber o currículo da Educação Infantil nas relações que acontecem nos encontros entre sujeitos e culturas alavanca "[...] significações que daí emergem enquanto respostas complexas às perguntas significativas e não mais fragmentos de conhecimentos específicos." (BARBOSA, 2009, p. 50).

Essa flexibilidade da ação docente envolve, fundamentalmente, a curiosidade das crianças, criando espaços-tempos para conhecerem, explorarem e atribuírem outros significados para suas experiências, numa pluralidade de sentidos em que a diferença é a mola propulsora. Ao refletirmos sobre estas mudanças de postura em relação ao processo educativo, afastamo-nos da ideia de currículo como prescrição para assumi-lo como "[...] criação, ação e narração do humano já que diz respeito ao agir e, portanto, ao risco e ao arriscar-se em linguagens." (RICHTER; BARBOSA, 2010, p. 94).

$\mathrm{Na}$ esteira de todas essas (re)invenções curriculares, encontramos problematizações acerca dos enfoques da organização dos espaços-tempos e das materialidades na Educação Infantil. Levantarmos esses aspectos torna-se pertinente tendo em vista que esta ecologia educativa (FOCHI, 2015) oferece ou não possibilidades para o fazer e o agir das crianças.

Compreender que as crianças têm outros modos de pensar, sentir e viver as experiências em sua inteireza (FOCHI, 2015), "no entrelaçamento entre corpo, emoção e linguagem" (MARI5EB), "Sabendo que na Educação Infantil o desenvolvimento das crianças está interligado com as oportunidades de aprendizagem que são oferecidas e provocadas pelo mundo que as cerca" (CAM2EB), traduz aspectos curriculares que denotam a ampliação de repertórios e sua integralidade.

Assim, tomarmos distância da frequente categorização e fragmentação de um mundo que precisa ser apresentado às crianças subentende assumir a investigação e a curiosidade como ferramentas para promover a interseção do lúdico com o cognitivo em diferentes linguagens.

Conforme Fochi (2015), a ludicidade, a continuidade e a significatividade são princípios relevantes para organizar as experiências infantis, num exercício docente ético, estético e político. Nessa perspectiva, considerar o comportamento lúdico como forma singular pela qual as crianças constroem sentidos para o mundo significa favorecer as invenções, formulações e experimentações das crianças. 
Compreender a noção de tempo como oportunidade no cotidiano remete ao princípio da continuidade, (re)construída pela vinculação entre os elementos sensíveis da vida cotidiana e sua relação com saberes e conhecimentos do patrimônio cultural. Construções essas significadas singularmente por cada criança, "(n)uma ideia de currículo [...] como um contexto fortemente educativo, que estimula a criança a dar significado, reorganizar e representar a própria experiência." (FOCHI, 2015, p. 226).

Isso significa percebermos o quanto a docência na Educação Infantil ainda é marcada por uma regulação temporal que empobrece a experiência da infância. Para Barbosa (2013), a ausência de tempo para escutarmos as crianças deriva de um enfoque centrado no preparo para o futuro, com o desenvolvimento de habilidades e a execução de trabalhos que instituem um ritmo acelerado. Essa velocidade, fruto da priorização da produtividade e de resultados uniformes, regula a fragmentação do tempo de forma fixa, o que acaba por sedimentar uma relação sistemática e racional em que o docente se volta para uma programação que esquece que:

São as crianças, em suas brincadeiras e investigações, que nos apontam os caminhos, as questões, os temas e os conhecimentos de distintas ordens que podem ser por elas compreendidos e compartilhados no coletivo. O professor, com seu olhar de quem está com a criança, mas também com os saberes e conhecimentos, realiza a complexa tarefa educacional de possibilitar encontros, de favorecer interações lúdicas, constituir tempos e espaços para a experiência das crianças [...]. (BARBOSA; RICHTER, 2015, p. 195).

Essa disponibilidade à escuta e à observação sensível das crianças foi evidenciada durante a construção de dados, quando em seus discursos os sujeitos da pesquisa mencionaram: "garantir às crianças serem protagonistas nas escolhas, conquistas e construções, sendo capazes de aprender $e$ desenvolver-se individualmente ou entre pares" (CÁT1EB), "porque eles ensinam muito mais que a gente imagina" (JOS/8GF), "Porque eles dão o significado àquele material que tu tá levando. Eles é que ressignificam aquele material." (CAM14S), "Olha o quanto de observação, a percepção dessas crianças... Isso é muito fantástico, isso é o que nos move! É isso que nos move!" (MAR/14S).

Investir na criação de contextos educativos exige um reposicionamento docente, no sentido de traçarmos estratégias para provocar o estabelecimento de relações e significações outras, sendo um caminho desafiador. O docente, ao se constituir sujeito dos saberes, rompe com o engessamento curricular e a busca incessante por resultados estipulados; em vez disso, aventura-se numa viagem repleta de indagações, numa aventura aberta ao possível em seus muitos caminhos, em que:

\footnotetext{
Nessa aprendizagem relacional emerge um tecido de desejos e indagações que desenvolvem uma variada e rica trama de relações com os saberes, com os sujeitos e com o mundo em que vivemos. Também entre o sujeito que aprende e a aprendizagem; entre o estabelecido e o emergente; entre os pensares, os sentires e as narrativas; entre o individual e o coletivo; entre o dentro e o fora; entre a escola, a família e a comunidade [...]. (CARBONELL, 2016, p. 207).
}

Levando essas premissas em consideração, durante a tessitura desta pesquisa decidimos concluir a trama de análise com uma imagem produzida pelos sujeitos no processo de construção de 
dados. Imagem essa que remetesse aos movimentos curriculares e às discussões pertinentes à cada seção em seus (entre)laçamentos.

Para concluirmos esta seção, escolhemos a poesia escrita pela Mirna para representar as conversações tecidas, envolvendo outros modos de pensar a docência na Educação Infantil. A emoção perpassou a dinâmica "essência Zezé", quando logo ao começar a ler a produção (figura 1), Mirna embargou a voz e encheu os olhos de lágrimas. Mais que resumirmos ou sintetizarmos traços pertinentes à escola ou à docência, a construção poética remete a inúmeros (entre)laçamentos que atravessam o âmago da Educação Infantil em sua pluralidade e diferença, sensibilidade e (in)segurança, ação e reflexão.

Figura 1 - Construção de dados - Sujeito: Mirna - Dinâmica "Essência Zezé"

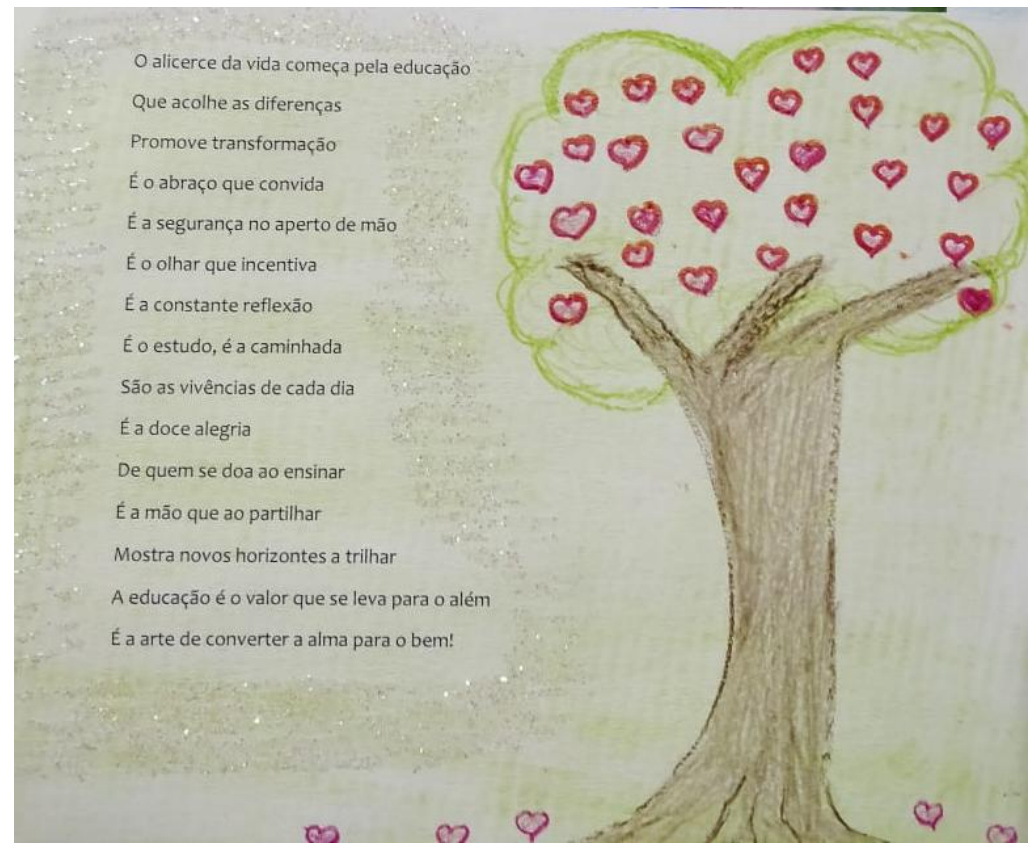

Fonte: Autoras (2019)

A processualidade e a (re)invenção permearam o texto, registrando as marcas de uma cultura pedagógica incerta, inquieta e plural que vem constituindo de forma crítica os processos de tornar-se docente na Educação Infantil. A emergência deste campo como espaço-tempo político, coletivo, plural, produtor de sentidos em que a expansão, a qualificação e o reconhecimento da Educação Infantil ainda estão se constituindo.

Configurar uma relação em que a prática é fonte de questionamento e produção da teoria, e não apenas de sua confirmação (CUNHA et al., 2001), propõe a possibilidade de os sujeitos recuperarem a partilha de seus caminhos subjetivos e a escolha de alternativas. Por meio da reflexão e do protagonismo, há espaço para a intencionalidade, para o desejo, para a inspiração, para a autoria, para a construção de novos conhecimentos e da própria professoralidade de outros modos. 


\section{CONSIDERAÇÕES FINAIS}

Acreditamos que entre tensões e contradições, (in)certezas, resistências e lutas, o campo da Educação Infantil vem se engendrando. Num olhar otimista, podemos dizer que as marcas desta recente história, pelo menos no que se refere à legalização, são positivas: os esforços das últimas décadas trouxeram avanços importantes, estabelecimentos legais que, com força, vem fomentando pesquisas, estudos e olhares outros acerca da infância, do ser criança e da necessidade de profissionalização da docência na Educação Infantil, bem como sua qualificação.

Num olhar pessimista, diríamos que muitas ainda são as urgências e as lacunas que estão em jogo: a efetivação da criança como sujeito de direitos, cidadã e produtora de cultura, a ampliação do acesso à Educação Infantil pública e gratuita, a melhoria de condições de creches e pré-escolas, o abandono de modelos pautados no preparo para Ensino Fundamental, entre tantas outras questões latentes.

A produção de sentidos nos movimentos desta pesquisa, entre desafios e possibilidades para a (re)invenção curricular em uma escola de Educação Infantil - nesse caso, da EMEI Zezé Tavares, localizada em Bagé/RS, fronteira oeste do Rio Grande do Sul, apontou para muitos (entre)laçamentos, lógicas que só puderam ser sentidas e compreendidas na e pela vivência cotidiana, pela atenção aos detalhes, pela sensibilidade ética e estética ao pesquisar.

Assim, essa pesquisa apontou os movimentos de autonomia pedagógica e de autoria crítica como elementos impulsionadores para alavancar outros modos de pensar a docência na Educação Infantil, partindo das interrogações que se apresentam cotidianamente com as crianças para provocar a desnaturalização de concepções infância, criança e de elementos curriculares como os espaçostempos e as materialidades.

Nos processos de dialogar e questionar-se acerca de experiências vividas cotidianamente na Educação Infantil os sujeitos da pesquisa mostraram a força do protagonismo docente. Protagonismo esse que, associado à ideia de autoria, pressupõe autonomia pedagógica, pertencimento, negociação, rompendo com relações regulatórias e lógicas impositivas, com a emergência da valorização de uma práxis e uma cultura democrática.

Para fomentar esse processo de autoria compartilhada, nesta investigação, lançamos mão das ferramentas da pesquisa-ação, a fim de que vozes, perspectivas, concepções e práticas dos sujeitos no campo do currículo da Educação Infantil ganhassem destaque enquanto (re)criação alicerçada nas demandas cotidianas e na ação-reflexão-ação.

$\mathrm{Na}$ pluralidade desse fazer-aprender junto, a horizontalidade nas relações aproximou os sujeitos da ação, que além de aprender e ensinar, compartilharam afetos, sensibilidades e sentimentos dos mais diversos. Esses movimentos reflexivos constantes apontaram para uma essência fecunda em (entre)laçamentos de forças e fraquezas, acertos e erros, que tomou os próprios limites e possibilidades como constituintes do currículo em processo de vivência coletiva.

Essas nuances, complexas e subjetivas, foram emergindo a partir de construções contingentes, pulsantes em vida, história, concepções e práticas, crenças e valores entrelaçados singularmente no 
currículo da instituição.

Enfatizamos que, nestas tramas emaranhadas que envolvem o currículo, repletas de relações entre limites e possibilidades - sejam eles/as laços, nós, brechas e/ou lacunas - pesquisar o currículo significou nos atrevermos a transitar, a assumir novas lentes, a reconsiderar caminhos e enfoques. Atentar para o cotidiano repleto de desafios e possibilidades, foi como nos entregarmos a um currículo vivo, um currículo aberto ao possível em seus muitos desafios.

\section{REFERÊNCIAS}

1. ARIZA, Leidy Gabriela; DIAS, Vânia de Morais Teixeira; SOUSA, Robson Simplício de; NUNES, Bruna Roman; GALIAZZI, Maria do Carmo; SCHMIDT, Elisabeth Brandão. Articulações metodológicas da Análise textual discursiva com o Atlas.ti: compreensões de uma comunidade aprendente. Investigação Qualitativa em Educação. Atas CIAIQ, v 2, 2015. Disponível em: https://proceedings.ciaiq.org/index.php/ciaiq2015/article/view/273/269. Acesso em: 20 abr. 2019.

2. BARBOSA, Maria Carmen Silveira. Práticas cotidianas na educação infantil: Bases para a reflexão sobre as orientações curriculares. Brasília: MEC/SEB, 2009.

3. BARBOSA, Maria Carmen Silveira. Tempo e cotidiano - tempos para viver a infância. Leitura: teoria e prática, Campinas, v. 31, n. 61, p. 213-222, nov. 2013. Disponível em: https://ttp.emnuvens.com.br/tp/article/view/185/122. Acesso em: 09 mar. 2019.

4. BARBOSA, Maria Carmen Silveira; RICHTER, Sandra. Campos de experiência: uma possibilidade para interrogar o currículo. In: FINCO, Daniela; BARBOSA, Maria Carmen Silveira; FARIA, Ana Lúcia Goulart de (orgs). Campos de experiências na escola da infância: contribuições italianas para inventar um currículo de educação infantil brasileiro. Campinas, SP: Edições Leitura Crítica, 2015.

5. BERTICELLI, Ireno Antonio. Currículo: tendências e filosofia. In: COSTA, Marisa Vorraber (org.). O currículo nos limiares do contemporâneo. Rio de Janeiro: DP\&A Editora, 1998.

6. BRASIL. Ministério da Educação. Secretaria de Educação Básica. Diretrizes curriculares nacionais para a educação infantil. Brasília, MEC, SEB, 2009.

7. BUJES, Maria Isabel Edelweiss. Infância e maquinarias. 259 f. 2001. Tese (Doutorado) Universidade Federal do Rio Grande do Sul - UFRGS, Programa de Pós-graduação em Educação, 2001. Disponível em: https://lume.ufrgs.br/bitstream/handle/10183/1904/000311899.pdf?sequence=1\&isAllowed=y. Acesso em: 05 jun. 2019. 
8. CARBONELL, Jaume. Pedagogias do século XXI: bases para a inovação educativa. 3.ed. - Porto Alegre: Penso, 2016.

9. CUNHA, Maria Isabel da; MARSICO, Heloísa Lamas; BORGES, Flávia Antônia; TAVARES, Patrícia. Inovações pedagógicas na formação inicial de professores. In: FERNANDES, Cleoni Maria; GRILLO, Marlene. (orgs.) Educação superior: travessias e atravessamentos. Canoas: Ed. ULBRA, 2001.

10. FOCHI, Paulo Sérgio. Ludicidade, continuidade e significatividade nos campos de experiência. In: FINCO, Daniela; BARBOSA, Maria Carmen Silveira; FARIA, Ana Lúcia Goulart de (orgs.). Campos de experiências na escola da infância: contribuições italianas para inventar um currículo de educação infantil brasileiro. Campinas, SP: Edições Leitura Crítica, 2015.

11. FRANCO, Maria Amélia Santoro. Pedagogia da pesquisa-ação. Educação e Pesquisa, São Paulo, v. $31, \quad$ n. $3, \quad$ p. 483-502, set./dez.2005. Disponível em: http://www.scielo.br/pdf/ep/v31n3/a11v31n3.pdf. Acesso em. 20 abr. 2019.

12. FRIESE, Susanne. Atlas.ti 8 Windows: Guia Rápido. ATLAS.ti Scientific Software Development $\mathrm{GmbH}$, Berlin, $2019 . \quad$ Disponível em: http://downloads.atlasti.com/docs/quicktour/QuickTour_a8_win_pt.pdf. Acesso em: 03 abr. 2019.

13. GATTI, Bernardete Angelina. Grupo focal na pesquisa em ciências sociais e humanas. Brasília: Líber Livro, 2005.

14. HADDAD, Lenira; CORDEIRO, Maria Helena; MONACO, Grégory Lo. As tarefas do professor de educação infantil em contextos de creche e pré-escola: buscando compreender tensões e oposições. Educação \& Linguagem, v. 15, n. 25, p. 134-154, jan./jul. 2012. Disponível em: https://www.metodista.br/revistas/revistas-ims/index.php/EL/article/view/3351/3071. Acesso em: 12 abr. 2019.

15. KUHLMANN JUNIOR, Moysés. Infância e educação infantil: uma abordagem histórica. Porto Alegre: Mediação, 2015

LOPES, Alice Casimiro; MACEDO, Elizabeth. Teorias do currículo. São Paulo: Cortez, 2011.

17. LOPES, Alice Casimiro; MACEDO, Elizabeth. Currículo: debates contemporâneos. $3^{a}$ edição. São Paulo: Cortez, 2010 
MACEDO, Elizabeth. Currículo como espaço-tempo de fronteira cultural. Revista Brasileira de Educação, v. $11, \quad$ n. 32 p. 285 - 296 maio./ago.2006. Disponível em: http://www.scielo.br/pdf/rbedu/v11n32/a07v11n32.pdf. Acesso em: 01 abr. 2019.

19. MORAES, Roque; GALIAZZI, Maria do Carmo. Análise textual discursiva. ljuí: Ed. Unijuí, 2007.

20. MOREIRA, Antônio Flávio; SILVA, Tomaz Tadeu da. Currículo, cultura e sociedade. 2. ed. São Paulo: Cortez, 1995.

21. OLIVEIRA, Meyre-Ester Barbosa de. Entre passagens: trilhas, rastos e descaminhos. In: FRANGELLA, Rita de Cássia (org.). Políticas curriculares, coordenação pedagógica \& escola: desvios, passagens e negociações. Curitiba: CRV, 2016.

OLIVEIRA, Valeska Fortes de. Glossário. In: MOROSINI, Marília (org.). Enciclopédia de pedagogia universitária. Porto Alegre, RS: FAPERGS/RIES, 2003.

OLIVEIRA, Zilma de Moraes Ramos de. Currículo na Educação Infantil: dos conceitos teóricos à prática pedagógica. In: SANTOS, Marlene Oliveira dos; RIBEIRO, Maria Izabel Souza. (orgs.). Educação Infantil os desafios estão postos e o que estamos fazendo? Salvador: Sooffset gráfica e editora Itda, 2014.

24. RICHTER, Sandra. Docência e formação cultural. In: BRASIL. Ser docente na educação infantil: entre o ensinar e o aprender. Ministério da Educação, Secretaria de Educação Básica. 1. ed. Brasília: MEC/SEB, 2016.

25. RICHTER, Sandra; BARBOSA, Maria Carmen da Silveira. Os bebês interrogam o currículo: as múltiplas linguagens na creche. Educação, Santa Maria, v. 35, n. 1, p. 85-96, jan./abr. 2010. Disponível em: https://periodicos.ufsm.br/reveducacao/article/view/1605/900. Acesso em: 01 jul. 2019.

26. ROSEMBERG, Fúlvia. Políticas públicas e qualidade da Educação Infantil. In: SANTOS, Marlene Oliveira dos; RIBEIRO, Maria Izabel Souza. (orgs.) Educação Infantil os desafios estão postos e o que estamos fazendo? Salvador: Sooffset Gráfica e Editora Ltda, 2014.

SALOMÃO DE FREITAS, Diana. A prática de pensar a prática de formação acadêmico-profissional de professoras(es) de ciências da natureza: estética do formar-se ao formar. 150 f. 2015. Tese (Doutorado) - Universidade Federal do Rio Grande - FURG, Programa de Pós-graduação em Educação em Ciências: Química da vida e Saúde, Rio Grande/RS, 2015. Disponível em: http://docplayer.com.br/57271307-A-pratica-de-pensar-a-pratica-de-formacao-academico- 
profissional-de-professoras-es-de-ciencias-da-natureza-estetica-do-formar-se-ao-formar.html. Acesso em: 03 abr. 2019.

THIOLLENT, Michel. Metodologia da Pesquisa-Ação. São Paulo: Cortez, 1986.

29. TRIPP, David. Pesquisa-ação: uma introdução metodológica. Revista Educação e Pesquisa v. 31, n. 3, p. 443-466, set./dez. 2005. Disponível em: http://www.scielo.br/pdf/ep/v31n3/a09v31n3.pdf. Acesso em: 10 abr. 2019.

\section{Adriana Rorato}

Graduação em Pedagogia pela Universidade da Região da Campanha (URCAMP); especialização em Gestão e Organização da Escola pela Universidade Norte do Paraná (UNOPAR - 2015) e em Educação Infantil pela Faculdade Educacional da Lapa (FAEL - 2017). É professora de Educação Infantil efetiva na Rede Municipal de Ensino de Bagé desde 2011; nos anos de 2012/2013 integrou o Setor de Educação Infantil do Departamento Pedagógico da Secretaria Municipal de Educação/SMED. Desde então atua como supervisora na Escola Municipal de Educação Infantil Zezé Tavares. Possui experiência na área da Educação Infantil e tem interesse especial pelas temáticas Infâncias, Currículo e Formação de Professores. É mestre pelo PPGMAE - Mestrado Acadêmico em Ensino da Universidade Federal do Pampa (UNIPAMPA - Bagé/RS) e membro do Grupo de Pesquisa em Inovação Pedagógica na Formação Acadêmico-Profissional de Profissionais da Educação (GRUPI).

\section{Elena Maria Billig Mello}

Graduação em Letras pela Faculdade de Filosofia Ciências e Letras de Cruz Alta (1985); especialização em Leitura (UNICRUZ, 1990); especialização em Educação -Supervisão Escolar (UNIJUÍ, 1990); mestrado em Educação pela Universidade Federal de Santa Maria (2002) e doutorado em Educação pela Universidade Federal do Rio Grande do Sul (2010). É professora e pesquisadora. Membro da Associação Nacional de Política e Administração da Educação (ANPAE), da Associação Nacional de Pós-Graduação e Pesquisa em Educação (ANPED) e da Rede Latinoamericana de Estudos sobre Trabalho Docente (Rede ESTRADO). Atuou como Pró-Reitora de Graduação da Universidade Federal do Pampa - UNIPAMPA, gestão 2012-2015. Vice-diretora da diretoria da ANPAE/RS. É professora associada na Universidade Federal do Pampa - UNIPAMPA, na graduação e pós-graduação. Coordenadora do curso de especialização lato sensu Neurociência aplicada à Educação (UNIPAMPA/Campus Uruguaiana). Líder do Grupo de Pesquisa em Inovação Pedagógica 
na Formação Acadêmico-Profissional de Profissionais da Educação (GRUPI). Tem experiência na área de Educação, com ênfase nos seguintes temas: valorização e formação de professores, formação acadêmico-profissional, inovação pedagógica, pedagogia universitária, política educacional, gestão da educação.

Como citar este documento:

RORATO, Adriana; MELLO, Elena Maria Billig. Quando o cotidiano interroga o currículo: outros modos de pensar a docência na Educação Infantil. Reflexão e Ação, Santa Cruz do Sul, v. 28, n. 2, jun. 2020. ISSN 1982-9949. Disponível em: <https://online.unisc.br/seer/index.php/reflex/article/view/14412>. Acesso em: doi:https://doi.org/10.17058/rea.v28i2.14412. 